\title{
Serum-based diagnosis of Pneumocystis pneumonia by detection of Pneumocystis jirovecii DNA and 1,3- $\beta$-D-glucan in HIV- infected patients: a retrospective case control study
}

Helena Hammarström ${ }^{1,2^{*}}$ D, Anna Grankvist ${ }^{1}$, Isabell Broman ${ }^{1}$, Nahid Kondori ${ }^{1}$, Christine Wennerås', Magnus Gisslen ${ }^{1}$ and Vanda Friman ${ }^{1}$

\begin{abstract}
Background: Pneumocystis jirovecii pneumonia (PCP) is one of the most common HIV-related opportunistic infections. The diagnosis of PCP is based on analyses from respiratory tract specimens which may require the invasive procedure of a diagnostic bronchoscopy. The objective of this study was to evaluate the diagnostic potential of Pneumocystis jirovecii PCR in serum combined with the 1,3- $\beta$-D-glucan (betaglucan) test for the diagnosis of PCP in HIV-infected patients.
\end{abstract}

Methods: This was a retrospective case-control study including serum samples from 26 HIV-infected patients with PCP collected within 5 days prior to the start of PCP treatment, $21 \mathrm{HIV}$-infected control subjects matched by blood $\mathrm{CD}^{+}$cell counts, and 18 blood donors. The serum samples were analyzed for Pneumocystis jirovecii PCR and betaglucan. The reference standard for PCP was based on previously described microbiological and clinical criteria.

Results: All patients with PCP had detectabe Pneumocystis jirovecii DNA in serum yielding a sensitivity for the Pneumocystis jirovecii PCR assay in serum of $100 \%$. All blood donors had negative Pneumocystis PCR in serum. The specificity when testing HIV-infected patients was 71\%, but with a PCR Cycle threshold (Ct) value of 34 as cut-off the specificity was $90 \%$. At a putative pretest probaility of $20 \%$, the negative and positive predictive value for the Pneumocystis PCR assay in serum was 0.99 and 0.71 , respectively. Betaglucan with cut-off level $200 \mathrm{pg} / \mathrm{ml}$ combined with a positive Pneumocystis jirovecii PCR result had sensitivity and specificity of 92 and 90\%, respectively. The concentration of Pneumocystis jirovecii DNA in serum samples, expressed by the PCR Ct values, correlated inversely to the betaglucan levels in serum.

Conclusion: In this case-control study including $70 \%$ of all HIV-infected patients with PCP treated at Sahlgrenska University Hospital during a time period of 13 years, Pneumocystis PCR analysis on serum samples had a very high sensitivity and negative predictive value for the diagnosis of PCP in HIV-infected patients. A serum-based diagnostic procedure either based on Pneumocystis jirovecii PCR alone or in combination with betaglucan analysis may thus be feasible and would facilitate the care of HIV-infected patients with suspected PCP.

Keywords: Pneumocystis jirovecii, Pneumocystis pneumonia, HIV, AIDS, Diagnosis, Polymerase chain reaction, 1,3-betad-glucan

\footnotetext{
* Correspondence: helena.hammarstrom@infect.gu.se

${ }^{1}$ Department of Infectious Diseases, Institute of Biomedicine, Sahlgrenska

Academy, University of Gothenburg, Gothenburg, Sweden

${ }^{2}$ Region Västra Götaland, Sahlgrenska University Hospital, Department of

Infectious Diseases, Gothenburg, Sweden
}

(c) The Author(s). 2019 Open Access This article is distributed under the terms of the Creative Commons Attribution 4.0 International License (http://creativecommons.org/licenses/by/4.0/), which permits unrestricted use, distribution, and reproduction in any medium, provided you give appropriate credit to the original author(s) and the source, provide a link to the Creative Commons license, and indicate if changes were made. The Creative Commons Public Domain Dedication waiver (http://creativecommons.org/publicdomain/zero/1.0/) applies to the data made available in this article, unless otherwise stated. 


\section{Background}

Pneumonia caused by the fungus Pneumocystis jirovecii $(P j)$ is one of the most common HIV-related opportunistic infections [1]. The diagnosis of Pneumocystis pneumonia (PCP) formerly relied solely on immunofluorescent staining and microscopic examination of the microorganism in samples from the lower respiratory tract, but polymerase chain reaction (PCR) methodology has been found to be more sensitive for the detection of $P j$ in respiratory specimens [2]. $P j$ DNA can also be detected by PCR in respiratory tract specimens from patients without clinical signs of pneumonia [3, 4], and $P j$ is now considered to be a frequent colonizer of the respiratory tract in patients with HIV [5-7].

$P j$ primarily resides in the alveoli of the lungs [8], and the concentration of the fungus is higher in specimens from the lower respiratory tract such as induced sputum and bronchoalveolar lavage (BAL) fluid than in upper respiratory tract specimens [9-11]. Consequently, induced sputum and BAL fluid are the recommended specimens for microbiological $P j$ analyses [12]. However, HIVinfected patients with PCP typically present with subacute onset of fever, dyspnoea and non-productive cough [13], and sputum samples may be difficult to obtain. The invasive procedure of a diagnostic bronchoscopy may thus be the only alternative to obtain respiratory specimens from HIV-infected patients for PCP diagnosis.

Previous studies have looked upon the possibility to use blood sample-based analyses for the microbiological diagnosis of PCP. In the 1990s some investigators using conventional PCR reported that Pj PCR performed on blood samples had too low sensitivity [2, 14-18]. Recent studies employing real-time PCR methodology show somewhat more promising results $[9,19,20]$. However, these studies lack well-defined clinical categorization of PCP versus $P j$ colonization and include mixed patient groups with various types of underlying immunosuppressive conditions making the results difficult to interpret in the context of PCP in HIV-infected patients.

1,3-ß-D-glucan (betaglucan), a polysaccharide that constitutes the major cell wall component of Pneumocystis jirovecii, can be detected in the serum of patients with PCP, and several studies have reported a good diagnostic performance in HIV-infected PCP patients [21-24].

To the best of our knowledge, there are no studies evaluating the diagnostic potential of combining bloodbased analyses of $P j$ DNA and betaglucan for the microbiological diagnosis of PCP in HIV-infected patients. The aim of this study was to evaluate whether Pj PCR and betaglucan analysis of blood samples could be a diagnostic alternative to the recommended Pj PCR performed on specimens from the lower respiratory tract in HIV-infected patients with PCP.

\section{Methods}

\section{Patients and control subjects}

Patients with HIV infection who had received a diagnosis of PCP at Sahlgrenska University Hospital in Gothenburg, Sweden between 2005 and 2018 were identified through the Swedish National Registry for HIV-care (InfCare HIV) [25]. The patients were included in the study provided that they had a serum sample frozen at $-80^{\circ} \mathrm{C}$ that had been collected within 5 days prior to the start of PCP treatment, and that they complied with the reference standard for PCP in this study, which was based on the following previously described criteria: $P j$ detected by PCR and/or microscopy with immunofluorescent staining in a sputum or BAL specimen; a minimum of two out of three clinical criteria of PCP (respiratory symptoms consisting of cough and/or dyspnoea, hypoxia, and typical radiological picture such as ground glass opacity on a chest computer tomography scan or diffuse interstitial opacity on chest $\mathrm{x}$-ray); receipt of a full course of treatment for PCP; and no other alternative aetiology to the clinical picture [26]. Compliance with the reference standard for PCP was independently assessed by two infectious disease specialists (H.H and M.G) prior to the analysis of the microbiological tests being evaluated (i.e. Pj PCR and betaglucan on serum samples). The severity of $\mathrm{PCP}$ was assessed based on the degree of hypoxemia $(\mathrm{PaO} 2 / \mathrm{FiO} 2$ index) within the first four days after start of PCP treatment and was categorized as mild ( $>200 \mathrm{mmHg}$ ) or severe $(\leq 200 \mathrm{mmHg})$ pneumonia $[27,28]$.

Twenty-one HIV-infected patients matched for blood $\mathrm{CD} 4{ }^{+}$cell counts who were admitted to the Department of Infectious Diseases at Sahlgrenska University Hospital during the same time period and who had not received a clinical diagnosis of PCP were identified through the Swedish National Registry for HIV-care and randomly selected as negative control subjects provided that they had a serum sample collected at the time of HIV diagnosis similarly stored at $-80^{\circ} \mathrm{C}$. Furthermore, serum samples from 18 blood donors were included as additional negative controls.

\section{Blood samples}

Serum samples stored at $-80^{\circ} \mathrm{C}$ from the patients with HIV and fresh serum samples from consecutive blood donors were analysed for betaglucan and Pj PCR at the Department of Clinical Microbiology at Sahlgrenska University Hospital. All analyses were performed by certified laboratory technicians who were blinded to the clinical data of the patients.

\section{Betaglucan}

The Glucatell ${ }^{\circ}$ assay kit (Ass. Cape Cod, MA, USA) was used for measuring serum levels of betaglucan by 
enzymatic reaction. The sera were pretreated and analyzed in duplicate according to the manufacturer's instructions. A betaglucan level $\geq 80 \mathrm{pg} / \mathrm{ml}$ is considered a positive result by the manufacturer, although several studies propose that a higher cut-off level may be preferable [21, 29]. Samples yielding betaglucan values above the maximum level of detection of the assay kit ( $>400 \mathrm{pg} / \mathrm{ml}$ ), were diluted 1:5 and reanalysed to yield a maximum detection limit of $2000 \mathrm{pg} / \mathrm{ml}$.

\section{Pneumocystis jirovecii real time PCR}

The real time PCR was performed using the BD MAX open mode System (BD Diagnostics, Franklin Lakes, New Jersey, US), which allows fully automated lysis of samples, DNA extraction and real-time PCR. The primers and probes targeting the mitochondrial gene coding for the large ribosomal subunit (mtLSU) of $P j$ previously described by Dini et al [30] were used with slight modifications: primers $F\left(5^{\prime}\right.$-AAA TAA ATA ATC AGA CTA TGT GCG ATA AGG-3') and R (5'-GGG AGC TTT AAT TAC TGT TCT GGG-3'); and Taq probe 5'-FAM-AGA TAG TCG AAA GGG AAA CMGB-3'. A total volume of $500 \mu \mathrm{L}$ of the sample was transferred into the BD MAX DNA-1 extraction kit (BD Diagnostic) Sample Buffer Tube, which contains a specimen processing control (SPC) that act as a control for extraction and PCR inhibition by the specimen. The PCR master mix was distributed in two different tubes snapped into the BD MAX extraction reagent strip. The first tube was the lyophilized BD MAX DNA MMK (SPC) reagents mix (BD Diagnostics), a universal master mix that also incorporates SPC primer and probe. The second master mix tube was prepared in-house and contained primers and probe $(1.6 \mu \mathrm{M}$ of each primer and $0.8 \mu \mathrm{M}$ of the probe), $2 \mu \mathrm{L}$ of primer diluent (provided by BD Diagnostics) and water to a final volume of $12.5 \mu \mathrm{L}$. Primers and probe mix were prepared and added to snap-in tubes at the start of the run. Cycling conditions were as follows: $98^{\circ} \mathrm{C}$ for $600 \mathrm{~s}$ and then 46 cycles of $96^{\circ} \mathrm{C}$ for $9 \mathrm{~s}$ and $62^{\circ} \mathrm{C}$ for $30.7 \mathrm{~s}$. A threshold of 100 units in endpoint fluorescence value was set to determine positive amplification together with approved SPC curve. Samples with non-approved SPC were re-analyzed once after dilution 1:2 in phosphate buffered saline. Prior to this study, 18 frozen concomitant plasma and serum samples from PCP patients and control patients with HIV were analyzed for $P j$ PCR in order to assess the most suitable blood fraction specimen for this PCR assay. In $72 \%$ of analyzed plasma samples, the specimen processing control of the PCR analysis was initially negative due to inhibiting factors in the plasma samples yielding inconclusive PCR results. The inhibition of the PCR analysis was overcome by a 1 : 2 dilution of the plasma samples. The analysis of serum samples yielded conclusive PCR results in the first round of analysis in $100 \%$ of the samples. Consequently, serum was considered the most suitable blood fraction for $P j$ PCR analysis.

\section{Statistics}

Comparison of proportions and comparison of medians were calculated by the Fisher's exact test and Mann Whitney U-test respectively. Sensitivity and specificity was calculated by cross tabulation with $95 \%$ confidence interval (CI). Predictive values were calculated by Bayes formula based on a pre-test probability of $20 \%$, consistent with the reported prevalence of PCP among HIV-infected patients with lung infection [31]. Correlation between Betaglucan and PCR cycle threshold $(\mathrm{Ct})$ values was assessed by using Spearman's correlation coefficient. GraphPad Prism 7.02 software (GraphPad Software Inc.) was used for statistical calculations. A $p$ value of $<0.05$ was considered statistically significant.

\section{Results}

A total of 37 HIV-infected patients with a clinical diagnosis of PCP were identified by the Swedish National Registry for HIV-care. Eleven patients that lacked a stored serum sample collected prior to the start of $\mathrm{PCP}$ treatment $(n=7)$ or that did not comply with the reference standard for PCP $(n=4)$ were excluded. This resulted in 26 patients with PCP eligible for the study. The study population thus included $70 \%$ of all HIV-infected patients with PCP treated at Sahlgrenska University Hospital during a time period of 13 years. All 26 patients had positive Pj PCR in sputum and/or BAL fluid, 9/26 patients also had microscopic examination with immunofluorescent staining performed where $8 / 9$ had a positive microscopy result. The median duration of respiratory symptoms prior to the collection of the stored serum samples was 28 days (range 4-75 days). All patients received treatment for PCP. Fourteen patients were classified as having a mild PCP and 12 patients had a severe PCP, out of which two patients died as a consequence of PCP. Twenty-four patients (92\%) had a favourable outcome.

The medical charts of the $21 \mathrm{HIV}$-infected control subjects registered in the Swedish National Registry for HIV-care as patients without PCP were reviewed to assure that no patients with $\mathrm{PCP}$ were erroneously included. No patients had a clinical diagnosis of PCP, but seven patients had respiratory symptoms. Three of these patients had radiological findings on chest $\mathrm{x}$-ray out of which one was diagnosed with tuberculosis. None of the patients had received trimethoprim-sulfamethoxazole in a therapeutic dose, but four patients received trimethoprim-sulfamethoxazole as PCP prophylaxis. A complete clinical assessment was not permitted due to the 
retrospective nature of the study; however, based on the available clinical data, none complied with the reference standard for PCP of this study. Consequently, and in order to avoid the risk of exclusion bias, these seven patients remained in the study despite the somewhat uncertain nature of the respiratory symptoms. The remaining 14 control patients had no respiratory symptoms nor clinical signs of opportunistic lung infection.

Background data and results of betaglucan and $P j$ PCR assays performed on serum samples from the HIV-infected patients with PCP, HIV-infected control subjects and blood donors are shown in Table 1. All PCP patients had $P j$ DNA in serum detected by PCR. None of the blood donors were positive by $P j$ PCR in serum, while 6/ 21 HIV-infected control patients (29\%) had Pj DNA in serum detectable by PCR. In total, $24 / 25$ patients with PCP $(96 \%)$ had positive betaglucan in serum $(\geq 80 \mathrm{pg} / \mathrm{ml})$ and $23 / 25$ (92\%) had betaglucan levels $\geq 200 \mathrm{pg} / \mathrm{ml}$. None of the blood donors had detectable betaglucan in serum.

The sensitivity and specificity of the $P j$ PCR and betaglucan assays performed on serum samples are shown in Table 2 . The Pj PCR assay had $100 \%$ sensitivity for PCP diagnosis in this study. The specificity was $100 \%$ when testing serum from blood donors, but $71 \%$ when testing serum samples from HIV-infected control subjects. Receiver operating characteristics curve analysis of PCR Ct values showed that a Ct value of 34 was the optimal cut-off level for this PCR-assay when performed on serum samples. When using a $\mathrm{Ct}$ value of $\leq 34$ as cutoff for a positive test result, the specificity increased to $90 \%$ with a retained high sensitivity of $96 \%$. Betaglucan analysis of serum samples had a sensitivity $>92 \%$ at cutoff levels 80 and $200 \mathrm{pg} / \mathrm{ml}$. The specificity of betaglucan was $100 \%$ when testing blood donors but $86 \%$ at cut-off level $200 \mathrm{pg} / \mathrm{ml}$ when testing the HIV-infected control subjects. When a combination of positive Pj PCR and betaglucan $\geq 200 \mathrm{pg} / \mathrm{ml}$ was used as the determinant of a positive test result, the specificity increased to $90 \%$.

The positive and negative predictive values of the $P j$ PCR and betaglucan assays performed on serum samples for the diagnosis of PCP at a putative pre-test probability of $20 \%$ [31] are shown in Table 3 . The negative predictive values of $P j \mathrm{PCR}$ and betaglucan at different cut-off levels for the diagnosis of PCP were very high overall $(>0.97)$. The highest positive predictive value (0.7) was found for the $P j$ PCR assay with $\mathrm{Ct}$ value $\leq 34$ as cut-off for a positive test result or for the combination of a positive $P j$ PCR and a betaglucan level $\geq 200 \mathrm{pg} / \mathrm{ml}$.

As mentioned above, six HIV-infected control patients had detectable $P j$ DNA in serum. Five of these patients belonged to the group of previously described control patients who had respiratory symptoms but who did not comply with the reference standard for PCP. The clinical characteristics of the six HIV-infected control subjects with positive $P j$ PCR results in serum are shown in Table 4. The median $\mathrm{Ct}$ value in serum of the $6 \mathrm{PCR}$ positive negative control patients was higher than that of the 26 PCR positive patients with PCP (38 and 29, respectively; $p<0.001$ ).

As shown in Fig. 1, the betaglucan levels tended to be higher in patients with higher concentrations of $P j$ DNA in serum, i.e. patients with lower PCR Ct values (Spearman's correlation coefficient $r=-0.5$ ). The patients with PCP and the serum PCR-positive control subjects tended to separate into two clusters where the majority of serum PCR-positive control subjects had higher Ctvalues and lower betaglucan levels.

Table 1 Patient characteristics and laboratory data

\begin{tabular}{llll}
\hline & $\begin{array}{l}\text { PCP } \\
\text { HIV-infected } \\
(n=26)\end{array}$ & $\begin{array}{l}\text { no PCP } \\
\text { HIV-infected } \\
(n=21)\end{array}$ & $\begin{array}{l}\text { Blood donors } \\
(n=18)\end{array}$ \\
\hline Age, yrs., median (range) & $47(25-70)$ & $38(23-64)$ & $46(18-59)$ \\
Females, n (\%) & $9(35)$ & $10(48)$ & $7(39)$ \\
CD4 ${ }^{+}$cell count, cells/uL, median (range) & $35(0-460)$ & $50(0-170)$ & - \\
Pj PCR in serum & & & $0(0)$ \\
Patients with positive results, n (\%) & $26(100)$ & $6(29)$ & - \\
Ct value, n, median (range) & $29(25-40)^{b}$ & $38(32-42)$ & $0(0)$ \\
BG in serum (pg/ml) & & & $0(0)$ \\
Patients with BG $\geq 80$ & $24(96)^{c}$ & $3(14)$ & $50(50-58)$ \\
Patients with BG $\geq 200$ & $23(92)^{c}$ & $50(50-2000)$ & \\
BG, median (range) & $1328(50-2000)^{c}$ & & \\
\hline
\end{tabular}

PCP Pneumocystis jirovecii pneumonia, Ct cycle threshold, BG 1,3-B-D-glucan

a Serum samples collected at hospital admission due to newly diagnosed HIV-infection

${ }^{\text {b}}$ The $\mathrm{Ct}$ values from three patients with PCP were excluded since their samples were diluted 1:2 prior to analysis

'One sample from a patient with PCP was not analyzed for BG due to insufficient volume of serum 
Table 2 Sensitivity and specificity of Pj PCR and betaglucan in serum

\begin{tabular}{|c|c|c|c|}
\hline \multirow[t]{3}{*}{ Index tests in serum } & \multirow{3}{*}{$\begin{array}{l}\text { Sensitivity (\%) }(95 \% \mathrm{Cl}) \\
\text { Patients with PCP } \\
n=26\end{array}$} & \multicolumn{2}{|l|}{ Specificity (\%) $(95 \%$ Cl) } \\
\hline & & HIV-infected control patients & Blood donors \\
\hline & & $n=21$ & $n=18$ \\
\hline Pj PCR positive & $100(87-100)$ & $71(50-86)$ & $100(87-100)$ \\
\hline Pj PCR with Ct $\leq 34^{\mathrm{a}}$ & $96(79-100)$ & $90(71-98)$ & $100(82-100)$ \\
\hline $\mathrm{BG} \geq 80 \mathrm{pg} / \mathrm{ml}^{\mathrm{b}}$ & $96(80-100)$ & $71(50-86)$ & $100(82-100)$ \\
\hline $\mathrm{BG} \geq 200 \mathrm{pg} / \mathrm{ml}^{\mathrm{b}}$ & $92(75-99)$ & $86(65-95)$ & $100(82-100)$ \\
\hline $\mathrm{BG} \geq 400 \mathrm{pg} / \mathrm{ml}^{\mathrm{b}}$ & $88(70-96)$ & $90(71-98)$ & $100(82-100)$ \\
\hline Pj PCR positive and $\mathrm{BG} \geq 200 \mathrm{pg} / \mathrm{ml}^{\mathrm{b}}$ & $92(75-99)$ & $90(71-98)$ & $100(82-100)$ \\
\hline
\end{tabular}

Pj Pneumocystis jirovecii, PCP Pneumocystis jirovecii pneumonia, Cl confidence interval, BG 1,3-ß-D-glucan

${ }^{a}$ Three PCP patients whose serum samples had been analysed after 1:2 dilution were excluded

${ }^{b}$ One PCP patient whose serum sample was not analyzed for BG due to insufficient volume of serum was excluded

PCR Ct values and betaglucan levels in serum in the patients with PCP, categorized into severity of disease, are presented in Fig. 2. There was a difference in median PCR Ct values and betaglucan levels in serum samples between patients with mild or severe PCP, but the difference did not reach statistical significance (Fig. 2).

Three of the patients with PCP did not have a sufficient volume of stored serum for the PCR analysis and the samples were diluted 1:2 with phosphate buffered saline prior to analysis. These three patients were excluded from the analyses that were dependent upon the PCR Cycle threshold $(\mathrm{Ct})$ values. One of them additionally lacked serum for the BG analysis.

\section{Discussion}

This study shows that real time-PCR analysis of $P j$ in serum is a highly sensitive method for PCP diagnosis in patients with HIV. In fact, all patients with PCP included in this study had detectable $P j$ DNA in serum giving a sensitivity of $100 \%$.

Previous studies from the 1990s evaluating the diagnostic potential of PCR for $P j$ using blood samples yielded conflicting results. Two studies evaluating $P j$ PCR performed on serum samples from a group of patients with PCP and various underlying immunosuppressive conditions showed a very low frequency of positivity (10\% or less) $[14,18]$. Other studies looking at circulating $P j$ DNA exclusively in patients with HIV showed diverging sensitivity estimates ranging from 0 to $86 \%$ [15-17, 32]. Nevertheless, these studies all employed conventional PCR methodology with manual DNA extraction with poorer precision and lower sensitivity for DNA detection compared to the automated DNA extraction and real time-PCR methodology used today. A more recent study evaluating concomitant BAL and serum samples from 63 patients with suspected pneumonia and various underlying immunosuppressive disorders showed that $9 / 10$ of patients with PCP and positive microscopic immunofluorescent analysis of BAL samples had circulating $P j$ DNA in serum detected by real time-PCR [19]. In analogy with our study, this suggests that with the more modern PCRs, Pj PCR performed on blood samples may indeed be an alternative for the diagnosis of PCP. On the other hand; in the same study, none out of 26 patients with negative microscopy but positive $P j$ PCR in BAL were positive for $P j$ in serum by PCR. However, the authors did not provide any clinical data, and it remains unclear whether these patients represented cases of clinical PCP or $P j$ colonization. Furthermore, only $4 \%$ of the patients in that study were HIV-infected, and considering that nonHIV patients with PCP tend to have a lower fungal

Table 3 Predictive values of Pj PCR and betaglucan in serum at a pre-test probability of 20\%

\begin{tabular}{lll}
\hline Index tests in serum & Positive predictive value & Negative predictive value \\
\hline$P j P C R$ positive & 0.46 & 1.0 \\
$P j P C R$ with $C t \leq 34^{a}$ & 0.71 & 0.99 \\
$B G \geq 80 \mathrm{pg} / \mathrm{ml}^{\text {b }}$ & 0.45 & 0.99 \\
$\mathrm{BG} \geq 200 \mathrm{pg} / \mathrm{ml}^{\mathrm{b}}$ & 0.63 & 0.98 \\
$\mathrm{BG} \geq 400 \mathrm{pg} / \mathrm{ml}^{\mathrm{b}}$ & 0.69 & 0.97 \\
$P j \mathrm{PCR}$ positive and $\mathrm{BG} \geq 200 \mathrm{pg} / \mathrm{ml}^{\mathrm{b}}$ & 0.70 & 0.98 \\
\hline
\end{tabular}

Pj Pneumocystis jirovecii, PCP Pneumocystis jirovecii pneumonia, BG 1,3-B-D-glucan

The results are based on 26 patients with PCP and 21 HIV-infected negative controls

${ }^{a}$ Three PCP patients whose serum samples had been analysed after 1:2 dilution were excluded

${ }^{b}$ One PCP patient whose serum sample was not analyzed for BG due to insufficient volume of serum was excluded 
Table 4 HIV-infected control patients with positive Pj PCR in serum

\begin{tabular}{|c|c|c|c|c|c|c|c|c|c|c|}
\hline \multirow[t]{2}{*}{ Pat } & \multirow{2}{*}{$\begin{array}{l}\text { CD4 } \\
\text { cell } \\
\text { count } \\
\text { (cells/ } \\
\mathrm{uL} \text { ) }\end{array}$} & \multicolumn{6}{|c|}{ Criteria of the PCP reference standard of this study } & \multirow[t]{2}{*}{ Outcome } & \multicolumn{2}{|c|}{ Index tests } \\
\hline & & $\begin{array}{l}\text { Respiratory } \\
\text { symptoms }\end{array}$ & $\begin{array}{l}\text { Radiologic } \\
\text { findings }\end{array}$ & Hypoxia & $\begin{array}{l}\text { Pj analysis } \\
\text { respiratory } \\
\text { specimen }\end{array}$ & TMP-SMX & $\begin{array}{l}\text { Other lung } \\
\text { infection }\end{array}$ & & $\begin{array}{l}\mathrm{BG} \\
(\mathrm{pg} / \\
\mathrm{ml})\end{array}$ & $\begin{array}{l}\text { Pj PCR in } \\
\text { serum Ct value }\end{array}$ \\
\hline 1 & 100 & Dry cough & Unknown & Unknown & Unknown & No & No & Survival & $>2000$ & 32 \\
\hline 2 & 30 & Dry cough & $\begin{array}{l}\text { Discrete } \\
\text { interstitial } \\
\text { opacity }\end{array}$ & Unknown & Unknown & $\begin{array}{l}\text { Prophylaxis } \\
\text { dose }\end{array}$ & No & Survival & 807 & 33 \\
\hline 3 & 10 & Dry cough & Normal & Unknown & Unknown & $\mathrm{No}^{\mathrm{b}}$ & No & Survival & $<50$ & 39 \\
\hline 4 & 80 & Dyspnea & Discrete GGO & Unknown & PCR neg ${ }^{a}$ & No & No & Survival & 60 & 38 \\
\hline 5 & 50 & $\begin{array}{l}\text { Productive cough } \\
\text { and dyspnea }\end{array}$ & Normal & No & PCR pos ${ }^{a}$ & $\begin{array}{l}\text { Prophylaxis } \\
\text { dose }\end{array}$ & No & Survival & 177 & 42 \\
\hline 6 & 50 & No & Normal & No & Unknown & No & No & Survival & $<50$ & 39 \\
\hline
\end{tabular}

PCP Pneumocystis jirovecii pneumonia, Pj Pneumocystis jirovecii, TMP-SMX trimethoprim-sulfamethoxazole, BG 1,3-ß-D-glucan, Ct Cycle threshold, GGO ground glass opacity

For patients where $P j$ analysis, radiological exam or measurement of $\mathrm{SpO}_{2}$ was not performed, the data is noted as unknown

${ }^{a} \mathrm{PCR}$ on sputum samples

${ }^{\mathrm{b}}$ received treatment for toxoplasmosis with pyrimethamine and sulphonamide

burden than HIV-infected patients with PCP [33], the results may not be relevant for HIV-infected patients. In another study on the same subject, where $98 \%$ of the included patients were HIV-infected, only $50 \%$ of the patients with positive $P j$ PCR in sputum had positive $P j$ PCR in a concomitant blood sample [9]. However, as in the aforementioned study, the authors did not make a clinical differentiation between PCP and $P j$ colonization. Moreover, $87 \%$ of the patients in that study had started empirical PCP treatment several days before blood sampling, which is likely to have contributed to the lower sensitivity reported compared to that of our study. Finally, in a very recent study, plasma samples were analysed by a Pneumocystis PCR assay in 80 HIV-infected patients who were diagnosed with PCP according to clinical routine. Also this study reported a lower sensitivity for blood sample-based $P j$ PCR than in our study. They found a $25 \%$ positivity-rate among patients with PCP, with a higher frequency of PCR-positivity in nonsurvivors than survivors [34]. However, details regarding the definition of PCP among included patients are not provided, and the authors do not report the use of any

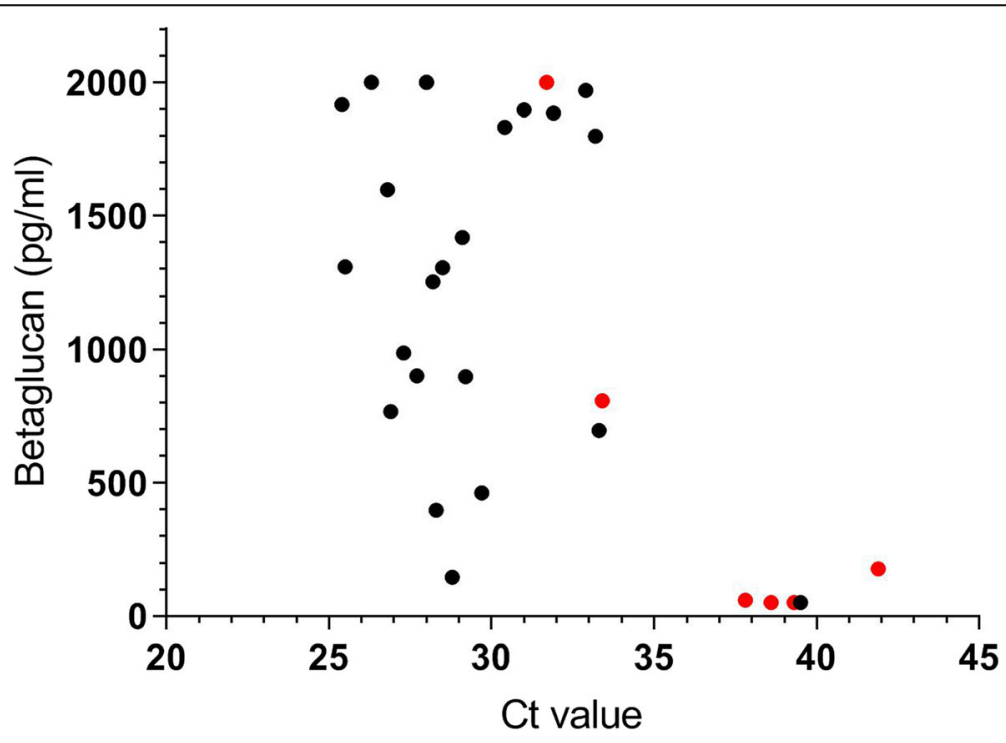

Fig. 1 Correlation of Betaglucan and PCR Ct values in serum. Values of betaglucan and PCR Ct in serum from 29 patients with positive Pj PCR in serum samples. Black dots represent patients with PCP $(n=23)$, and red dots represent HIV-infected controls $(n=6)$. Three patients with 1:2 diluted serum samples out of which one also had inconclusive BG result were excluded. Correlation was assessed by Spearman's correlation coefficient: $r=-0.5(-0.7$ to -0.1$), p<0.01$ 

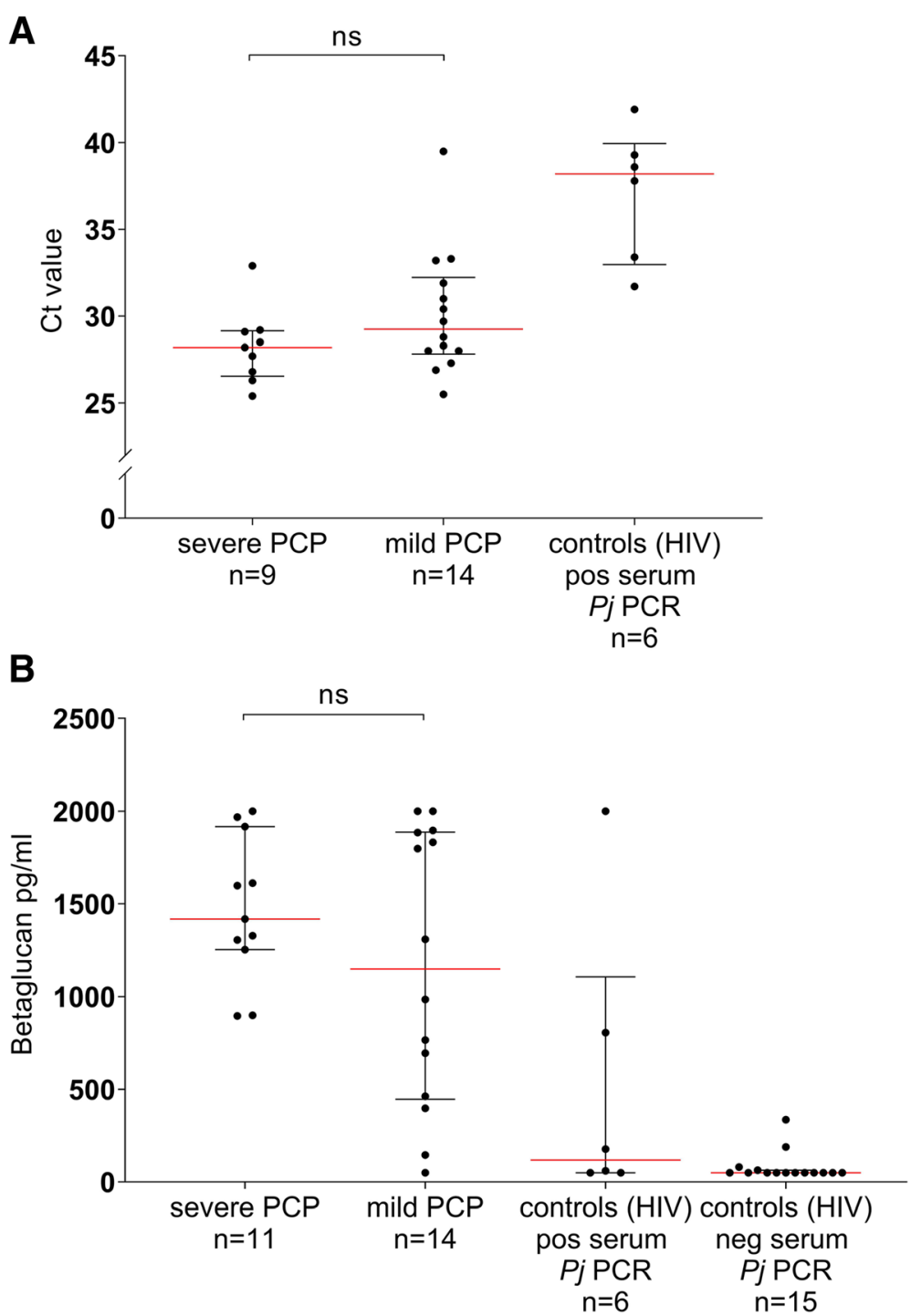

Fig. 2 PCR Ct values and Betaglucan levels in serum in patients with severe and mild PCP and in HIV-infected control subjects. Ct values (a) and Betaglucan levels (b) with medians and interquartile ranges in serum samples obtained from patients with severe, mild and no Pneumocystis pneumonia (PCP). Medians were compared by Mann Whitney U-test. Three PCP patients whose serum samples had been analysed after 1:2 dilution (a) and one patient whose serum sample was not analyzed for BG due to insufficient volume of serum (b) were excluded

specific reference standard for PCP. Additionally, they used plasma samples for PCR analysis as opposed to our study where serum samples were used. In our pilot analysis aimed at evaluating different blood fractions for $P j$ PCR analysis, we found a high rate of PCR-inhibition when using plasma samples. This was not found for serum samples. The authors of this study do not report how inconclusive PCR results were handled, why the results are difficult to compare.

In contrast to the previous studies, the results of our study were based on a reference standard for PCP including previously defined clinical criteria. This makes it more likely that the patients representing the target disease group in our study truly suffered from PCP rather than $P j$ colonization, which may explain the higher sensitivity of $P j$ PCR in serum found in our study. Furthermore, differences in blood sample fractions, DNA extraction protocols and PCR-assays used in the different studies may also account for differences in diagnostic accuracy. Nevertheless, the number of patients included in our study was limited, why the results need to be further investigated in prospective longitudinal studies.

The specificity of the Pj PCR assay used in our study was $100 \%$ when performed on serum samples from blood donors, but only $71 \%$ when the control subjects consisted of HIV-infected patients; i.e. six HIV-infected negative controls had detectable $P j$ DNA in serum by 
PCR. It was found that seven of the HIV-infected patients selected as negative controls had respiratory symptoms; however, the retrospective nature of the study did not allow for a full evaluation of the etiology of the clinical picture, and in order to avoid the risk of exclusion bias, these patients were allowed to remain in the study. Our results showed that 5/7 of these control patients with respiratory symptoms in fact were patients with so called false positive PCR results. The possibility that some of these control patients with positive $P j$ PCR results in serum may in fact have had an undiagnosed and self-limiting PCP [35] and that the specificity of the PCR assay thus was underestimated cannot be ruled out. Another hypothetical explanation to the detection of circulating $P j$ DNA in serum in the control patients with no definite PCP may be the escape of fungal DNA, derived from Pneumocystis organisms colonizing the lower respiratory tract, into the circulation. We found that the median $\mathrm{Ct}$ values were higher, i.e. the concentrations of $P j$ DNA in the serum samples were lower in the Pj PCRpositive control patients than in the patients with PCP. In analogy with this, other studies have shown that $P j$ PCR Ct values in BAL samples are higher in patients with $\mathrm{Pj}$ colonization than in patients with PCP $[36,37]$.

We thus hypothesized that the use of a determined $\mathrm{Ct}$ value as cut-off for a positive $P j$ PCR-result in serum may help to discriminate true cases of PCP from patients with circulating $P j$ DNA but no manifest PCP. This proved to be true, and when using a $\mathrm{Ct}$ value of 34 as the determinant of a positive PCR-result in serum, the specificity increased to $90 \%$ with only a minor loss of sensitivity from 100 to $96 \%$. Important to note, however, is that since the $\mathrm{Ct}$ depends on the specific PCR reaction, the $\mathrm{Ct}$ value of 34 proposed as a cut-off for a positive PCR result in this study may not be the most suitable cut-off for other PCR assays.

In our study, we found a sensitivity of $96 \%$ for betaglucan at a cut-off level of $80 \mathrm{pg} / \mathrm{ml}$, which confirms the results of previous reports [21-24] showing that betaglucan in serum is a highly sensitive marker for the diagnosis of PCP in HIV-infected patients. Similar to the Pj PCR assay in serum, the specificity of betaglucan in serum at the lowest cut-off level of $80 \mathrm{pg} / \mathrm{ml}$ was quite low $(71 \%)$ when using HIV-infected patients as control subjects. However, the combination of the two serum analyses Pj PCR and betaglucan with cut-off level 200 $\mathrm{pg} / \mathrm{ml}$ yielded sensitivity and specificity above $90 \%$, suggesting a very high diagnostic performance for $\mathrm{PCP}$ in HIV-infected patients.

It was previously shown that approximately $20 \%$ of HIV-infected patients presenting with clinical signs of lung infection have PCP [31]. With a preset pre-test probability of $20 \%$, the negative predictive values of the Pj PCR or betaglucan assay in serum in our study were very high. This suggests that any of these diagnostic markers may be used to rule out PCP in an HIV-infected patient with clinical sign of lung infection.

Previous studies suggest that betaglucan levels in serum may correlate to the Pneumocystis fungal load in respiratory samples $[19,38]$ and that betaglucan levels are higher in HIV-infected patients with PCP than in those colonized by $P j$ [21]. We hypothesized that the serum betaglucan levels would correlate to the fungal burden in serum as assessed by the Pj PCR Ct values in the serum samples, and that $\mathrm{Ct}$ values and betaglucan levels might be of use to discriminate between mild and severe Pneumocystis disease among patients with PCP. We did find a negative correlation between betaglucan levels and $\mathrm{Ct}$ values in serum; however, we did not find any significant difference in median $\mathrm{Ct}$ values or betaglucan levels between patients with mild or severe PCP. This implies that the betaglucan level may be correlated to the fungal burden in blood; however, the fungal burden may not be correlated to the severity of Pneumocystis pneumonia. In analogy with these results, other authors have previously reported that the fungal burden in respiratory samples does not correlate to the severity of PCP in patients with HIV [24].

\section{Conclusions}

In summary, this study shows that real time-PCR analysis of $P j$ in serum samples is a sensitive method with a high negative predictive value for the diagnosis of PCP in patients with HIV, and our results suggest that a negative PCR result in serum may be used to rule out the infection. Furthermore, if using a $\mathrm{Ct}$ value of 34 as cut-off for a positive PCR result in serum or if combining a positive $P j$ PCR result with a betaglucan level in serum $>200 \mathrm{pg} / \mathrm{ml}$ as the determinant of a positive test result, the specificity for the diagnosis of PCP is high. Although further longitudinal studies are warranted in order to draw firm conclusions, we here present a promising first assessment of serum-based microbiological analyses of Pneumocystis jirovecii showing that this non-invasive diagnostic approach may be an alternative method for the diagnosis of PCP in HIV-infected patients.

\footnotetext{
Abbreviations

BAL: Bronchoalveolar lavage; Betaglucan: 1,3- $\beta$-D-glucan; Cl: Confidence interval; Ct: Cycle threshold; GGO: Ground glass opacity; HIV: Human immunodeficiency virus; PCP: Pneumocystis jirovecii pneumonia; PCR: Polymerase chain reaction; Pj: Pneumocystis jirovecii; TMPSMX: Trimethoprim-sulfamethoxazole

\section{Acknowledgements} Not applicable.

Authors' contributions

$H H, V F$ and MG designed the study, analyzed the data and drafted the manuscript. AG and IB made substantial contributions to collection of data and data analysis. NK and CW made substantial contributions to the draft and acquisition of the work and to interpretation of data. All authors
} 
participated in revision of the manuscript and approved the submitted version of the manuscript.

\section{Funding}

This work was supported by Sahlgrenska University Hospital [grant numbers ALF 70150, ALF 74140] and the Gothenburg Medical Society [grant number GLS 717831].

\section{Availability of data and materials}

The datasets used and/or analyzed during the current study are available from the corresponding author on reasonable request.

\section{Ethics approval and consent to participate}

The study was approved by the Regional Ethics Committee in Gothenburg (Reg nr 735-18) and performed in accordance with the ethical standards of the 1964 declaration of Helsinki and its later amendments. In accordance with the Regional Ethics Committee consent from the patients was not needed due to the retrospective nature of the study. All patients had previously given informed consent for storage of serum samples in a biobank according to a prior approval by the Regional Ethics Committee (Ö 588-01). The stored serum samples were used according to the national regulations of the National Biobank Council.

\section{Consent for publication}

Not applicable.

\section{Competing interests}

The authors declare that they have no competing interests.

\section{Received: 22 March 2019 Accepted: 16 July 2019}

\section{Published online: 23 July 2019}

\section{References}

1. Buchacz K, Baker RK, Palella FJ Jr, Chmiel JS, Lichtenstein KA, Novak RM, et al. AIDS-defining opportunistic illnesses in US patients, 1994-2007: a cohort study. Aids. 2010;24(10):1549-59.

2. Lipschik GY, Gill VJ, Lundgren JD, Andrawis VA, Nelson NA, Nielsen JO, et al. Improved diagnosis of Pneumocystis carinii infection by polymerase chain reaction on induced sputum and blood. Lancet. 1992:340(8813):203-6.

3. Peterson JC, Cushion MT. Pneumocystis: not just pneumonia. Curr Opin Microbiol. 2005:8(4):393-8.

4. Wilson JW, Limper AH, Grys TE, Karre T, Wengenack NL, Binnicker MJ. Pneumocystis jirovecii testing by real-time polymerase chain reaction and direct examination among immunocompetent and immunosuppressed patient groups and correlation to disease specificity. Diagn Microbiol Infect Dis. 2011:69(2):145-52

5. Davis JL, Welsh DA, Beard CB, Jones JL, Lawrence GG, Fox MR, et al. Pneumocystis colonisation is common among hospitalised HIV infected patients with non-Pneumocystis pneumonia. Thorax. 2008;63(4):329-34.

6. Huang L, Crothers K, Morris A, Groner G, Fox M, Turner JR, et al. Pneumocystis colonization in HIV-infected patients. J Eukaryot Microbiol. 2003;50(Suppl):616-7.

7. Morris A, Kingsley LA, Groner G, Lebedeva IP, Beard CB, Norris KA. Prevalence and clinical predictors of Pneumocystis colonization among HIVinfected men. Aids. 2004;18(5):793-8.

8. Smulian AG, Walzer PD. The biology of Pneumocystis carinii. Crit Rev Microbiol. 1992;18(3):191-216.

9. van Halsema C, Johnson L, Baxter J, Douthwaite S, Clowes Y, Guiver M, et al Short communication: diagnosis of Pneumocystis jirovecii pneumonia by detection of DNA in blood and oropharyngeal wash, compared with sputum. AIDS Res Hum Retrovir. 2016;32(5):463-6.

10. Helweg-Larsen J, Jensen JS, Benfield T, Svendsen UG, Lundgren JD, Lundgren B. Diagnostic use of PCR for detection of Pneumocystis carinii in oral wash samples. J Clin Microbiol. 1998:36(7):2068-72

11. Matos $O$, Costa MC, Lundgren B, Caldeira L, Aguiar P, Antunes F. Effect of oral washes on the diagnosis of Pneumocystis carinii pneumonia with a low parasite burden and on detection of organisms in subclinical infections. Eur J Clin Microbiol Infect Dis. 2001;20(8):573-5.

12. Masur H, Brooks JT, Benson CA, Holmes KK, Pau AK, Kaplan JE. Prevention and treatment of opportunistic infections in HIV-infected adults and adolescents: updated guidelines from the Centers for Disease Control and
Prevention, National Institutes of Health, and HIV medicine Association of the Infectious Diseases Society of America. Clin Infect Dis. 2014;58(9):1308-11.

13. Norris KA, Morris A, Patil S, Fernandes E. Pneumocystis colonization, airway inflammation, and pulmonary function decline in acquired immunodeficiency syndrome. Immunol Res. 2006;36(1-3):175-87.

14. Roux P, Lavrard I, Poirot JL, Chouaid C, Denis M, Olivier JL, et al. Usefulness of PCR for detection of Pneumocystis carinii DNA. J Clin Microbiol. 1994; 32(9):2324-6.

15. Atzori C, Agostoni F, Angeli E, Mainini A, Orlando G, Cargnel A. Combined use of blood and oropharyngeal samples for noninvasive diagnosis of Pneumocystis carinii pneumonia using the polymerase chain reaction. Eur J Clin Microbiol Infect Dis. 1998;17(4):241-6.

16. Tamburrini E, Mencarini P, Visconti E, Zolfo M, De Luca A, Siracusano A, et al. Detection of Pneumocystis carinii DNA in blood by PCR is not of value for diagnosis of P. carinii pneumonia. J Clin Microbiol. 1996;34(6):1586-8.

17. Rabodonirina M, Cotte L, Boibieux A, Kaiser K, Mayencon M, Raffenot D, et al. Detection of Pneumocystis carinii DNA in blood specimens from human immunodeficiency virus-infected patients by nested PCR. J Clin Microbiol. 1999;37(1):127-31.

18. Wagner D, Koniger J, Kern W, Kern P. Serum PCR of Pneumocystis carinii DNA in immunocompromised patients. Scand J Infect Dis. 1997;29(2):159-64.

19. Costa JM, Botterel F, Cabaret O, Foulet F, Cordonnier C, Bretagne S. Association between circulating DNA, serum (1->3)-beta-D-glucan, and pulmonary fungal burden in Pneumocystis pneumonia. Clin Infect Dis. 2012;55(2):e5-8.

20. Wang D, Hu Y, Li T, Rong HM, Tong ZH. Diagnosis of Pneumocystis jirovecii pneumonia with serum cell-free DNA in non-HIV-infected immunocompromised patients. Oncotarget. 2017;8(42):71946-53.

21. Esteves F, Lee $\mathrm{CH}$, de Sousa B, Badura R, Seringa M, Fernandes C, et al. (1-3)beta-D-glucan in association with lactate dehydrogenase as biomarkers of Pneumocystis pneumonia (PCP) in HIV-infected patients. Eur J Clin Microbiol Infect Dis. 2014;33(7):1173-80.

22. Sax PE, Komarow L, Finkelman MA, Grant PM, Andersen J, Scully E, et al. Blood (1->3)-beta-D-glucan as a diagnostic test for HIV-related Pneumocystis jirovecii pneumonia. Clin Infect Dis. 2011;53(2):197-202.

23. Wood BR, Komarow L, Zolopa AR, Finkelman MA, Powderly WG, Sax PE. Test performance of blood beta-glucan for Pneumocystis jirovecii pneumonia in patients with AIDS and respiratory symptoms. Aids. 2013;27(6):967-72.

24. Watanabe T, Yasuoka A, Tanuma J, Yazaki H, Honda H, Tsukada K, et al. Serum (1-->3) beta-D-glucan as a noninvasive adjunct marker for the diagnosis of Pneumocystis pneumonia in patients with AIDS. Clin Infect Dis. 2009;49(7):1128-31.

25. Gisslen M, Svedhem V, Lindborg L, Flamholc L, Norrgren $H$, Wendahl S, et al. Sweden, the first country to achieve the joint United Nations Programme on HIV/AIDS (UNAIDS)/World Health Organization (WHO) 90-90-90 continuum of HIV care targets. HIV medicine. 2017;18(4):305-7.

26. Esteves F, Cale SS, Badura R, de Boer MG, Maltez F, Calderon EJ, et al. Diagnosis of Pneumocystis pneumonia: evaluation of four serologic biomarkers. Clin Microbiol Infect. 2015:21(4):379 e1-10.

27. Sun J, Su J, Xie Y, Yin MT, Huang Y, Xu L, et al. Plasma IL-6/IL-10 ratio and $\mathrm{LL}-8, \mathrm{LDH}$, and $\mathrm{HBDH}$ level predict the severity and the risk of death in AIDS patients with Pneumocystis pneumonia. J Immunol Res. 2016;2016:1583951.

28. Ranzani OT, Prina E, Menendez R, Ceccato A, Cilloniz C, Mendez R, et al. New Sepsis definition (Sepsis-3) and community-acquired pneumonia mortality. A validation and clinical decision-making study. Am J Respir Crit Care Med. 2017;196(10):1287-97.

29. Hammarstrom $\mathrm{H}$, Kondori $\mathrm{N}$, Friman $\mathrm{V}$, Wenneras $\mathrm{C}$. How to interpret serum levels of beta-glucan for the diagnosis of invasive fungal infections in adult high-risk hematology patients: optimal cut-off levels and confounding factors. Eur J Clin Microbiol Infect Dis. 2015;34(5):917-25.

30. Dini L, du Plessis M, Frean J, Fernandez V. High prevalence of dihydropteroate synthase mutations in Pneumocystis jirovecii isolated from patients with Pneumocystis pneumonia in South Africa. J Clin Microbiol. 2010:48(6):2016-21.

31. Benito N, Moreno A, Miro JM, Torres A. Pulmonary infections in HIV infected patients: an update in the 21st century. Eur Respir J. 2012; 39(3):730-45.

32. Schluger N, Godwin T, Sepkowitz K, Armstrong D, Bernard E, Rifkin M, et al. Application of DNA amplification to pneumocystosis: presence of serum Pneumocystis carinii DNA during human and experimentally induced Pneumocystis carinii pneumonia. J Exp Med. 1992;176(5):1327-33. 
33. Kovacs JA, Hiemenz JW, Macher AM, Stover D, Murray HW, Shelhamer J, et al. Pneumocystis carinii pneumonia: a comparison between patients with the acquired immunodeficiency syndrome and patients with other immunodeficiencies. Ann Intern Med. 1984;100(5):663-71.

34. Wang $M$, Dai $X$, Huang $Y$, Sun J, Dong $X$, Guo $Y$, et al. The presence of Pneumocystis jirovecii DNA in plasma is associated with a higher mortality rate in patients with AIDS-associated Pneumocystis pneumonia. Med Mycol. 2018. 57(5):582-7.

35. Prickartz A, Lusebrink J, Khalfaoui S, Schildgen O, Schildgen V, Windisch W, et al. Low Titer Pneumocystis jirovecii Infections: More than Just Colonization? J fungi (Basel). 2016;2(2):1-8.

36. Fauchier T, Hasseine L, Gari-Toussaint M, Casanova V, Marty PM, Pomares C. Detection of Pneumocystis jirovecii by quantitative PCR to differentiate colonization and pneumonia in immunocompromised HIV-positive and HIVnegative patients. J Clin Microbiol. 2016:54(6):1487-95.

37. Robert-Gangneux F, Belaz S, Revest M, Tattevin P, Jouneau S, Decaux O, et al. Diagnosis of Pneumocystis jirovecii pneumonia in immunocompromised patients by real-time PCR: a 4-year prospective study. J Clin Microbiol. 2014; 52(9):3370-6.

38. Damiani C, Le Gal S, Da Costa C, Virmaux M, Nevez G, Totet A. Combined quantification of pulmonary Pneumocystis jirovecii DNA and serum (1->3)beta-D-glucan for differential diagnosis of pneumocystis pneumonia and Pneumocystis colonization. J Clin Microbiol. 2013;51(10):3380-8.

\section{Publisher's Note}

Springer Nature remains neutral with regard to jurisdictional claims in published maps and institutional affiliations.

Ready to submit your research? Choose BMC and benefit from:

- fast, convenient online submission

- thorough peer review by experienced researchers in your field

- rapid publication on acceptance

- support for research data, including large and complex data types

- gold Open Access which fosters wider collaboration and increased citations

- maximum visibility for your research: over $100 \mathrm{M}$ website views per year

At $\mathrm{BMC}$, research is always in progress.

Learn more biomedcentral.com/submissions 